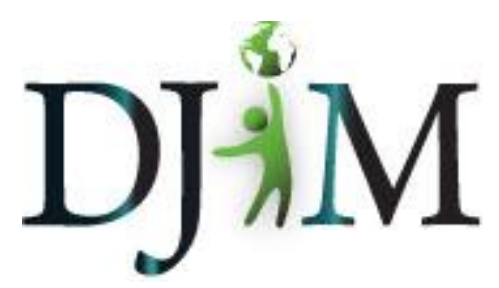

Volume 7 - Spring 2011 djim.management.dal.ca

\title{
DJIM Volume 7: A Year of Change and Growth
}

\section{Amy Paterson}

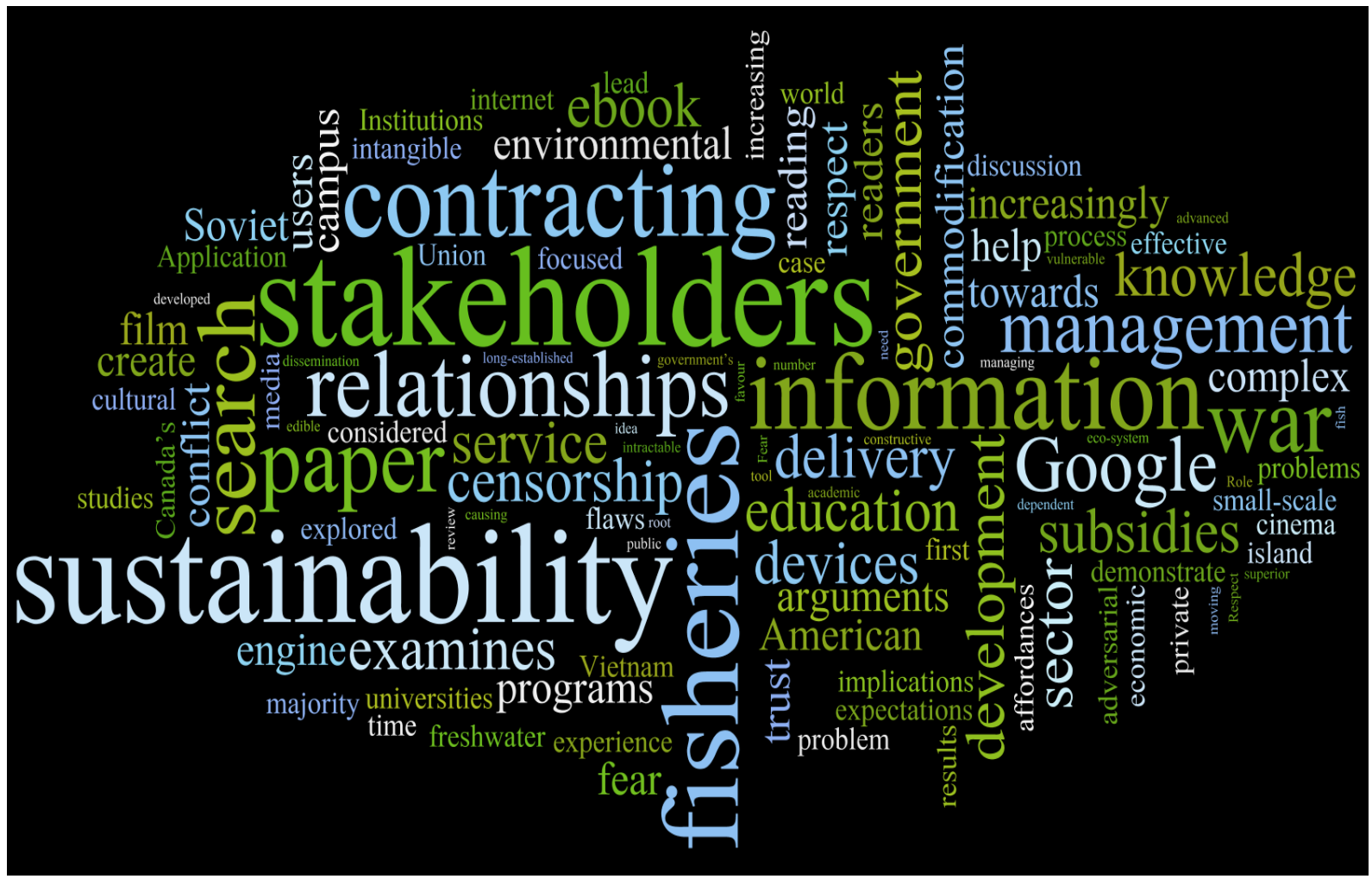

DJIM Wordle created by Naomi Balla-Boudreau and Katie Marshall

About the Author: Amy Paterson is a graduating MLIS student from Dalhousie's School of Information Management. There is nothing she will miss more about the program than being Editorial Chair of DJIM. 


\section{Welcome to Volume 7}

On behalf of the Executive of the Dalhousie Journal of Interdisciplinary Management, I am extremely proud to introduce our seventh volume. It has been a year of incredible changes for us, and we hope that our efforts have resulted in an all-around better journal for our readers. As always, our goal is to reflect the best in research and writing from Dalhousie's Faculty of Management, and this year for the first time, we will be publishing articles submitted from all four of Dalhousie's Management Schools.

Change seems to be a prominent thread through our articles this year. Heather MacFadyen's article "The Reader's Devices: The Affordances of Ebook Readers" examines this new media of reading and its effect on readers' experiences and expectations. Others like Joey O'Brien's "No Magic Solution: An Examination of the Arguments in Favour of Contracting out Government Services" considers possible change and reflects on the potential future of government. This theme of future government paths and a reflection on current practices continues in Kaitlan Lay's "Subsidies and their Implications on Fisheries Management in St. Lucia." Lay examines her issue with a focus on environmental sustainability, a theme that continues in Rebecca McNeil's "Application of Knowledge Management for Sustainable Development in Institutions of Higher Education."

Environmental concerns present themselves again in Mark McGinley's "The Effect of Respect, Trust, and Fear in Adversarial Stakeholder Relationships: A Case Study on Water Commodification and Stakeholder Engagement;" McGinley examines the issue of Canada's freshwater in an attempt to promote ethical business and stakeholder relations. Ethics were also on Stephanie Winston's mind when writing her article, "Don't be Evil: Uncovering the Implications of Google Search," where she examines the larger societal effect of what has become instinctual behaviour to so many. Jacqueline Phinney's article, "And That's the Way It Is: The Media's Role in Ending the Vietnam War" also takes a fascinating look at somewhat unexpected implications, concentrating on the pervading influence of the media. In contrast to Winston, however, Phinney ruminates on potentially more positive effects. Finally, Lora Hamilton also considers the relationship of popular media to information in her article, "Cinema during the First Two Decades of the Soviet Union: How Censorship of the Arts Inhibits the Dissemination of Information." The collision of historical precedent with the ever-present idea of censorship rounds out the ideas of interdisciplinarity, change and growth seen in all of the articles published this issue.

Other changes in DJIM may be less prominent, but are still just as significant. Starting this year, DJIM will be available with more features in more places. All of our back issues are now searchable in the Directory of Open Access Journals (DOAJ), and you can follow all of our updates on Facebook and Twitter as DalhousieDJIM. Perhaps the biggest change of all is our newly-remastered website. Readers can register to get more involved as authors and peer 
reviewers, while anyone can access our enhanced tools, such as links to email the author, find out how to cite an article, or share an issue with friends or colleagues.

Some of these efforts have already made an impact, as this year we received a record number of submissions, almost doubling last year's numbers. In fact, because of the record amount of interest, this year we will be dividing our articles across two issues. Look for the second issue of Volume 7 in Fall 2011. Until then, thank you for reading, and, as always, we look forward to hearing your feedback!

\section{Acknowledgements}

This latest issue of the Dalhousie Journal of Interdisciplinary Management would not be possible without the time and effort of a number of people and groups. Our Executive Committee, Departmental Liaisons, Editorial Team and Technical Team all contributed greatly to the success of this issue. This year, extra special thanks go out to Geoff Brown, who helped us get the new website up and running and has been so kind to troubleshoot all of our issues on that front. We also owe a great debt to Lara Killian, our former Editorial Chair, who was an excellent host of our peer reviewer workshop; finally, Laura Landon whipped all the copyeditors into shape by the loan of her time, resources, and exceptional instruction. Of course, DJIM would never exist without the hard work of our volunteer peer reviewers and copyeditors. These include:

\section{Student Peer Reviewers}

David Arron

Naomi Ball-Boudreau

Jennifer Givens Bishop

Amanda Bulman

Tracy Daley

Alyssa Graybeal

Jeanna Greene

Lora Hamilton

Sheila Lucas

Katie MacDonald

Craig MacEachern
Katie Marshall

Mark McHale

Katie McLean

Rebecca McNeil

Jacqueline Phinney

Samantha Read

Melissa Scanlan

Douglas Seaman

Kimberly Senf

Kathleen Staves

Nicole Tanner 
Kae Yee Tsai

Tammy Whynot

\section{Faculty Peer Reviewers}

Dr. Michelle Adams, SRES

Dr. Peter Duinker, SRES

Dr. Anatoliy Gruzd, SIM

Dr. Vivian Howard, SIM

Dr. Keith Lawson, SIM

Dr. Ed Leach, SBA

Joyline Makani, SIM/SBA

\section{Copyeditors}

Jennifer Givens Bishop

Heather Buchanan

Ian Buchanan

Jeanna Greene

Jennifer Grek Martin

Lora Hamilton

Katie MacDonald

Craig MacEachern
Amanda Wilk

Mary Zazelenchuk

Dr. Bertrum MacDonald, SIM

Paul McKenna, SIM

Dr. Stéphane Mechoulan, SPA

Dr. Binod Sandararajan, SBA

Dr. Kate Sherren, SRES

Dr. Louise Spiteri, SIM

Sandra Toze, SIM

Kate MacKeigan

Amy Paterson

Kathleen Staves

Nicole Tanner

Monica Ward

Stephanie Winston

Mary Zazelenchuk 